and Spring months. Further analysis of these trends is required to establish a cause and effect relationship for initiation and discontinuation of domiciliary NIV in clinical practice.

\section{P275 AN AFFERENT RESERVOIR ENABLES THE NIPPY 1 TO DELIVER ANY GAS}

doi:10.1136/thoraxjnl-2011-201054c.275

R Richards. Princess Royal University Hospital, Orpington, Kent, UK

Non-invasive ventilation with some gas mixtures, such as high flow oxygen or Heliox, can be problematic and/or require expensive equipment. The addition of a pressurised afferent reservoir to the Nippy 1 ventilator ( $B \& D$ Electromedical) was studied to see if this would overcome these problems. The remote trigger of the Nippy 1 is essential to this design. A CPAP circuit was used to give a gas flow of at least $30 \mathrm{l} / \mathrm{m}$; a $30 \mathrm{~cm} \mathrm{H}_{2} \mathrm{O}$ safety valve was incorporated. A 31 afferent reservoir (bag in bottle design) was added via a t-tube (Abstract P275 figure 1). The inner flexible bag was directly open to the CPAP circuit. The rigid outer casing had two ports, the first connected to the output from the Nippy 1 and the second connected to and exhaust valve controlled by the Nippy 1. A standard Nippy 1 breathing circuit conveyed the gas to the patient. As the patient breaths in the Nippy 1 is triggered and closes the two exhaust valves. The reservoir is pressurised by the ventilator providing a positive inspiratory pressure. In expiration both valves open enabling the patient to breathe out and the reservoir to refill. Pressure measurements at the mask showed that the system has an intrinsic PEEP of approximately $2.5 \mathrm{~cm} \mathrm{H} \mathrm{H}_{2} \mathrm{O}$; the trigger on the Nippy 1 was changed to a relative design to compensate. The circuit can be adjusted to deliver inspiratory pressures of up to $30 \mathrm{~cm} \mathrm{H}_{2} \mathrm{O}$. The pressure performance was unaltered when using Heliox, oxygen or air. The addition of a CPAP valve to the patient exhaust port could also be employed to raise the PEEP pressures as required. The development of this circuit may enable any gas to be used within the HDU/CCU setting without needing expensive equipment.

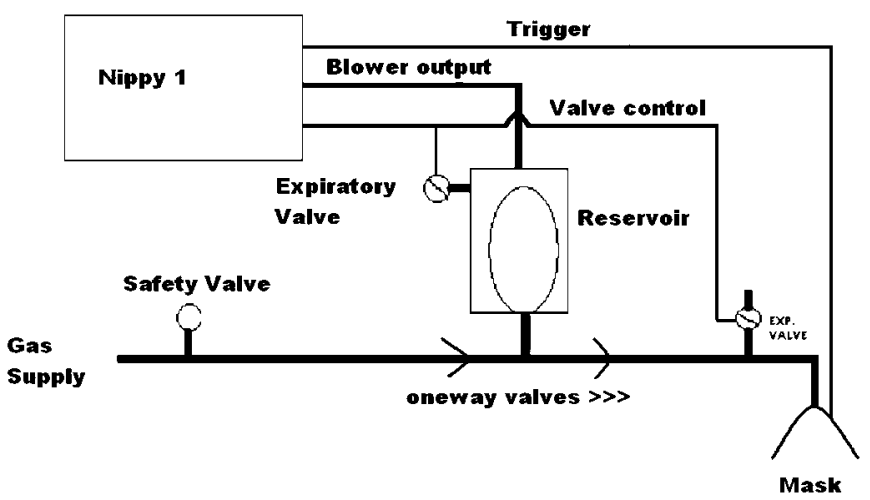

Abstract P275 Figure 1

\section{P276 THE VALUE OF VITAL CAPACITY AND DAYTIME PULSE OXIMETRY TO PREDICT HYPERCAPNIA IN OBESE PATIENTS}

doi:10.1136/thoraxjnl-2011-201054c.276

${ }^{1}$ E Boleat, 'S Mandal, ${ }^{1} \mathrm{E}$ Suh, ${ }^{1,2} \mathrm{~N}$ Hart. ' Lane Fox Respiratory Unit, Guy's St Thomas NHS Foundation Trust, London, UK; ' ${ }^{2}$ Uuy's and St Thomas' NHS Foundation Trust and
King's College London, National Institute of Health Research Comprehensive Biomedical Research Centre, London, UK

Introduction The Health Survey for England reported that 25\% of UK adults are obese with a $10 \%$ rise over 15 years. Consequently, clinicians are faced with a rising number of obese patients referred for bariatric and non-bariatric surgery. Previous data indicates a $50 \%$ incidence of obstructive sleep apnoea in patients with a BMI $>40 \mathrm{~kg} / \mathrm{m}^{2}$ with obesity hypoventilation syndrome present in up to a third. These patients have higher risk of peri-operative complications. A screening tool to predict hypercapnic respiratory failure $\left(\mathrm{P}_{\mathrm{a}} \mathrm{CO}_{2}>6 \mathrm{kPa}\right)$ based on simple clinic tests would be useful. Correlations were performed to determine which tests may be useful.

Methods Data from all obese patients (BMI $>30 \mathrm{~kg} / \mathrm{m}^{2}$ ) with evidence of sleep-disordered breathing on oximetry initiated on home ventilatory support between August 2005 and December 2010 were obtained from a discharge summary database.

Results 205 patients were included for analysis. The group mean age was 54.9 (SD 14.2) years, daytime clinic oxygen saturations $\left(\mathrm{SpO}_{2 \text { clinic }}\right)$ 91.0\% (5.8\%), $\mathrm{FEV}_{1} 1.81$ (0.96 l), FVC 2.21 (1.11 l), weight $132.8 \mathrm{~kg}(28.5 \mathrm{~kg})$, BMI $47.6 \mathrm{~kg} / \mathrm{m}^{2}$ (9.6) and Epworth sleepiness score 8.9 (5.6). Mean daytime $\mathrm{P}_{\mathrm{a}} \mathrm{CO}_{2}$ was $6.68 \mathrm{kPa}(1.31$ ). Significant correlations were found between $\mathrm{P}_{\mathrm{a}} \mathrm{CO}_{2}$ and $\mathrm{BMI}$ $(\mathrm{r}=0.20 ; \mathrm{p}<0.005), \mathrm{FEV}_{1} \%$ predicted $(\mathrm{r}=-0.20 ; \mathrm{p}<0.005), \mathrm{FVC} \%$ predicted $(\mathrm{r}=-0.20 ; \mathrm{p}<0.005)$ and $\mathrm{SpO}_{2 \text { clinic }}(\mathrm{r}=-0.52 ; \mathrm{p}<0.005)$. Receiver operating characteristics (ROC) analysis was used to determine the utility of $\mathrm{SpO}_{2 \text { clinic }}$ and FVC to predict hypercapnia. The area under the curve (AUC) for $\mathrm{SpO}_{2 \text { clinic }}$ was $0.81(\mathrm{p}<0.001)$; a cut-off of $\mathrm{SpO}_{2 \text { clinic }}$ of $<92 \%$ demonstrated a sensitivity of $86 \%$ and specificity of $52 \%$ in predicting hypercapnia. The AUC for FVC was found to be $0.77(p<0.0001)$; a cut-off of $<1.941$ demonstrated a sensitivity of $77 \%$ and specificity of $61 \%$ in detecting hypercapnia (see Abstract P276 figure 1).

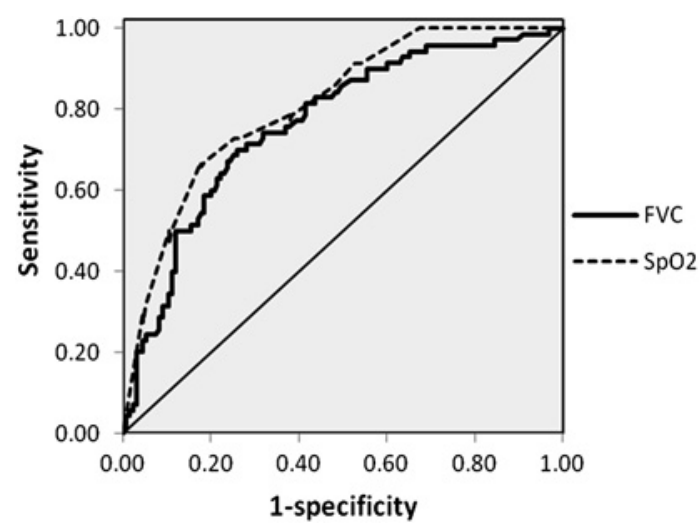

Abstract P276 Figure 1 Receiver operating characteristics for FVC and $\mathrm{SpO}_{2 \text { clinic }}$ in predicting hypercapnia.

Conclusion These data have significant clinical utility for clinicians involved in providing respiratory support services for obese patients undergoing bariatric and non-bariatric surgery. In particular, it could form the foundations of a screening algorithm including simple measures such as home oximetry, spirometry and clinic pulse oximetry, to identify the highest risk patients that need to be reviewed by sleep and ventilation clinicians. 